\title{
Using Multi-Angular Radar Data to Discriminate the Influence of Rough Surface Scattering on Soil Moisture Inversions over Bare Soils
}

\author{
Benô̂t Molineaux ${ }^{1}$, André Chanzy ${ }^{1}$ and M. Zribi $^{2}$ \\ ${ }^{1}$ Institut National de Recherche Agronomique \\ Science du Sol, Domaine St-Paul, Agroparc, 84914 Avignon Cedex, France \\ Tel: +33 4903161 20,fax: +33 49031 62 44, molineau@avignon.inra.fr, achanzy@avignon.inra.fr \\ ${ }^{2}$ CETP/CNRS, 10, 12, avenue de l'Europe, 78140, Velizy, France, zribi@cetp.ipsl.fr
}

\begin{abstract}
It is well known that the angular response of radar backscattering is strongly influenced by surface roughness. Attempts to exploit this result in soil moisture or roughness inversions are however practically non-existent, maybe because multi angular satellite data are only starting to be available. Experimental data shows how the difference between signals at $20^{\circ}$ and $30^{\circ}$ incidence angles is $10 \mathrm{x}$ more sensitive to surface roughness degradation than is the difference between hh and $\mathrm{vv}$ polarizations at same incidence and 5.3 or $9.4 \mathrm{GHz}$. Extensive simulations with IEM show that this result can be exploited for soil moisture inversions, if the surface correlation function is close to exponential.
\end{abstract}

\section{INTRODUCTION}

Retrieving soil moisture from radar data over bare soils is an outstanding challenge due to the influence of rough surface scattering (RSS). The range of sensitivity of the radar signal to RSS over natural soils is more than twice that due to soil moisture variations. Moreover, the number of surface parameters that are necessary to quantify the effect of RSS is shown to be a minimum of three, whereas only a single variable parameter is necessary to quantify the effect of soil moisture.

Numerically, RSS can be quantified if the entire surface geometry as viewed by the radar is known with sufficient resolution [1]. Analytically, the state of the art model to date, IEM $[2,4]$, gives an alternative theoretical approach that relies only on a few input parameters. The IEM, in its practical version, however remains dependent on the statistical laws that are used to describe random roughness as well as various approximations inherent to its analytical form, which greatly restrict its domain of validity.

Experimentally, the clear dependence of radar signal to soil moisture (see § 3) makes it tempting to propose empirical models that reproduce the observations. It is however generally admitted that existing empirical models are valid only over the range of surface roughness characteristics over which they were developed. Moreover, because of the multiple surface roughness parameters, it is difficult to find simple models that cover a wide range of surface characteristics. This is made clear below with IEM simulations over a wide range of surface roughness parameters.
Since multiple parameters influence the radar signal, it seems inevitable to have recourse to multiple measurements of the same surface, viewed under different conditions, to discriminate the different effects. The difference between signals measured at two view angles is presented here as a potential candidate to eliminate the influence of RSS on the radar signal, thus opening the possibility of inverting the corrected signal to retrieve soil moisture.

Experimentally, the potential of this method seems promising. From IEM simulations however, it is shown that the method is not practical unless the surface correlation function is close to the exponential. This was investigated for a wide range of surface parameters and incident angles from $20^{\circ}$ to $40^{\circ}$, which are typical of satellite remote sensing,

\section{MODEL FORMULATION}

In a practical approximation, the effects of RSS and soil

moisture on the radar signal can be written as

$$
\sigma_{0}=f_{1}\left(\theta_{i}, \mathrm{RSS}\right)+f_{2}\left(\theta_{i}\right) \cdot f_{3}\left(m_{v}\right)[\mathrm{dB}]
$$

where RSS represents the combined surface roughness parameters, $\theta_{\mathrm{i}}$ is the incidence angle and $m_{v}$ is the soil moisture. The separation of functions $f_{2}$ and $f_{3}$ is based on our simulated and experimental results, see $\S 3$. The separation of $f_{1}$ from $\left(f_{2} \cdot f_{3}\right)$ has been used before [3] and is confirmed by our experimental and IEM-simulated results.

Based on (1), it is easy to show :

$$
\begin{aligned}
\Delta \sigma & =\sigma_{0}\left(\theta_{1}\right)-\sigma_{0}\left(\theta_{2}\right) f_{2}\left(\theta_{1}\right) / f_{2}\left(\theta_{2}\right) \\
& =f_{1}\left(\theta_{1}, \operatorname{RSS}\right)-f_{1}\left(\theta_{2}, \operatorname{RSS}\right) f_{2}\left(\theta_{1}\right) / f_{2}\left(\theta_{2}\right)
\end{aligned}
$$

Thus, if (1) is respected, it is possible, from two measurements at different angles, to obtain a quantity in [dB] which is dependant only on surface roughness parameters and not on soil moisture.

In $\S 3,(1)$ and (2) are validated with both experimental and simulated data. The proposed method can be divided in 3 steps: i) estimate $\Delta \sigma$ from measurements at two angles; $i$ ) determine $f_{1}$ from $\Delta \sigma$ and iii) estimate the soil moisture $m_{v}$ from (1), with the knowledge of $f_{1}, f_{2}$ and $\sigma_{0}$. 


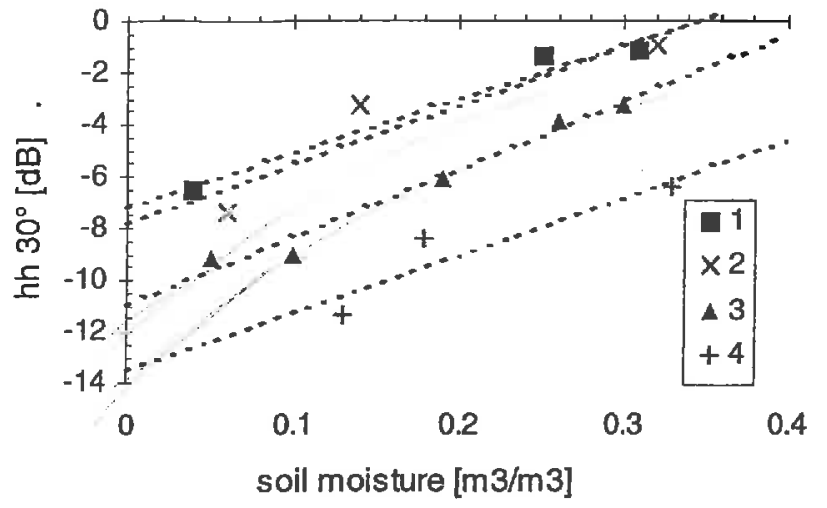

Figure 1: Measured signal versus measured soil moisture. Radar on crane. Pixel area $\sim 10 \times 10 \mathrm{~m}$. Four data sets $=$ four periods consecutive to rain or irrigation. rms height $-1.4,1.2$,

1.0 and $0.8 \mathrm{~cm}$ for periods $1-4$. Frequency is $9.4 \mathrm{GHz}$.

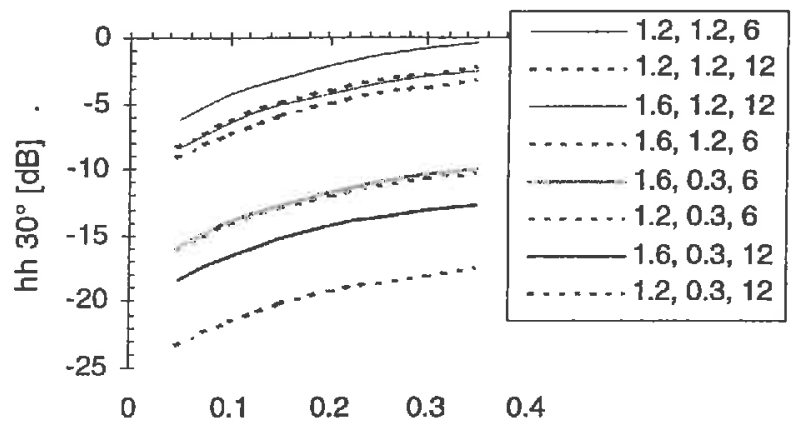

soil moisture [m3/m3]

Figure 3: IEM simulated radar backscatter versus soil moisture. The triplets represent $\mathrm{D}, k s$, and $k l$, where $\mathrm{D}$ is the fractal dimension, $k$ is the wave number and $s, l$ are the surface rms height and correlation length.

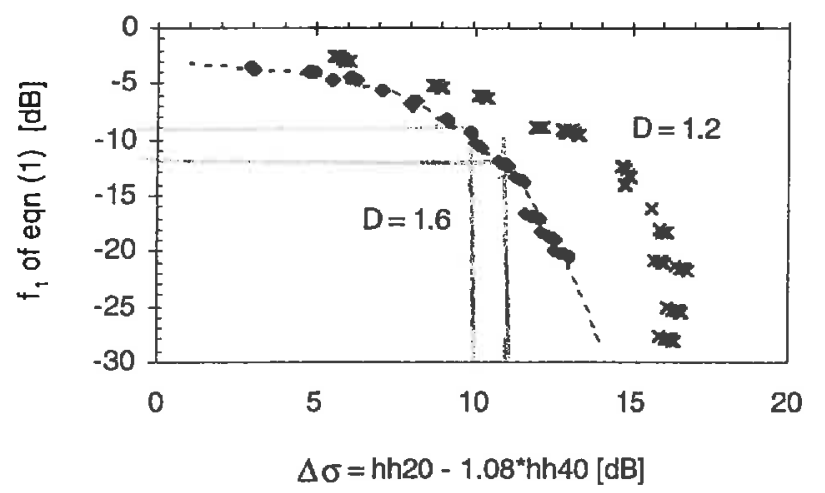

Figure 5: IEM simulation, $f_{1}$ of (1) versus $\Delta \sigma$ of (2) for $k s=$ 0.3 to $1.5, k l=6$ to 12 and two surface correlation functions symbolized by $D$, the fractal dimension. The smallest values of $f_{1}$ (largest $\Delta \sigma$ ) occur when the rms height is smallest.

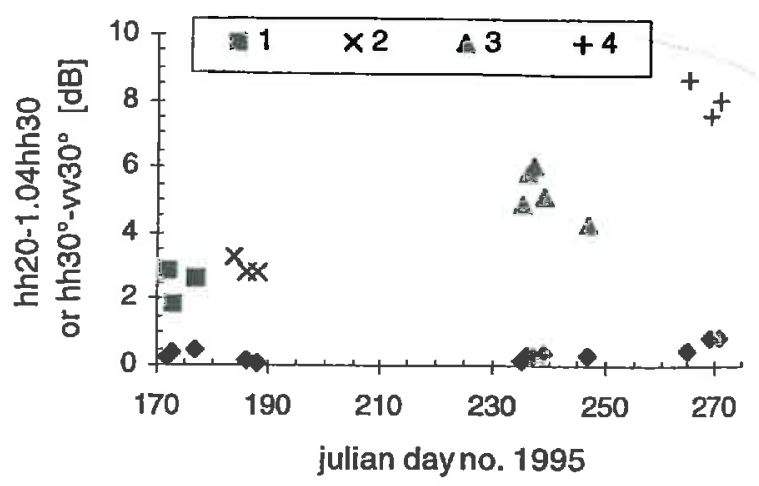

Figure 2: Difference between radar signals measured at two incidence angles (red) and two polarizations (blue) versus day number. Same sets of data as Fig. 1. The increase is due to smoothing under the action of rain or irrigation before each of the four periods.

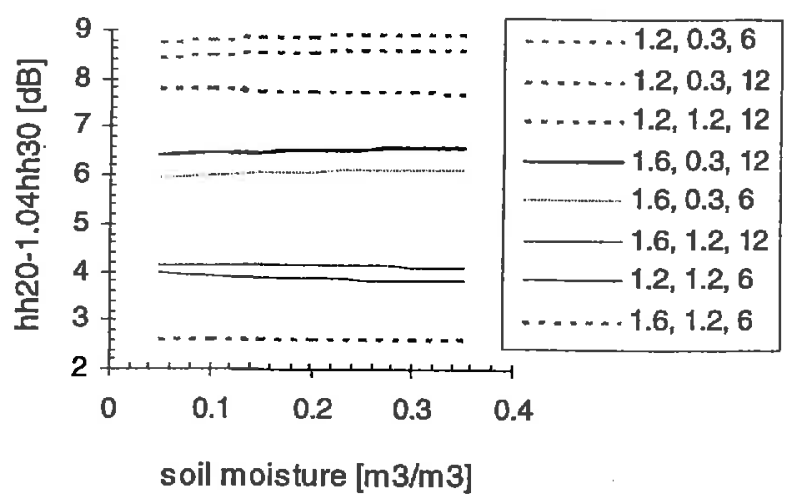

Figure 4: $\Delta \sigma$ as simulated by IEM versus variable surface characteristics - D, $k s, k l$ - as in Fig. 3. Note that $\mathrm{D}=1.6$ to 1.0 represents a variation from exponential to gaussian correlated surface [5] and $k=1 \mathrm{~cm}^{-1}$ if the frequency is $4.77 \mathrm{GHz}$.

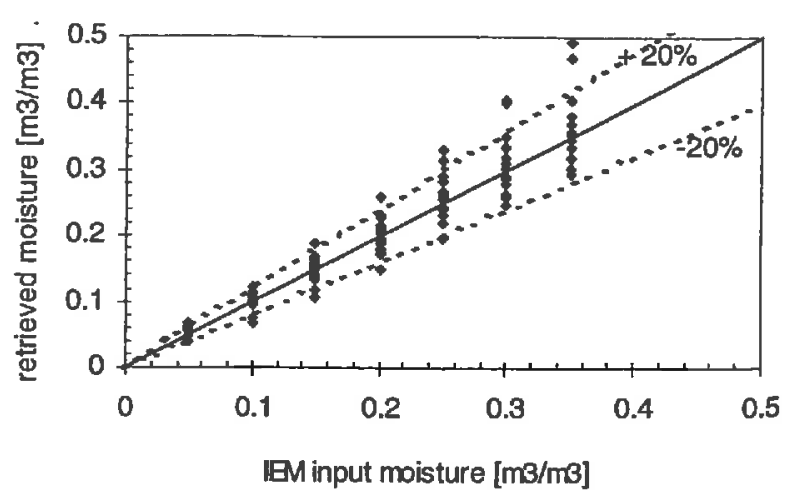

Figure 6: Simulated moisture retrieval using (1-3), over the same data set as used in Fig. 5, assuming an exponential surface correlation, see text. Note that the largest errors occur when the soil is "smoothest" and $f_{1}$ is minimal, see Fig. 5. 
WATER FLOW AND SOIL WATER CONTENT VARIABILITY IN GRASSWATER FLOW AND SOIL WATER CONILS OF THE NETHERLANDS

Louis W. Dekker and Coen J. Ritsema

DLO Winand Staring Centre for Integrated Land, Soil and Water Research (SC-DLO)

PO Box 125, NL-6700 AC Wageningen. The Netherlands

Tel:+31-317-474267; Fax: +31-317-424812; E-mail:1.w.dekker@sc.dlo.n!

In the Netherlands many grass-covered heavy clay and peat soils are susceptible to drought and difficult to wet after a dry period. A major proportion of precipitation can flow rapidly through shrinkage cracks towards the subsoil, bypassing the matrix of the flow rapidly through shrinkage cracks the soils revealed that preferential flow is not soils. However, trenches studied in these soils revealed that preferential flow is not limited to macropore flow: irregular and fingeriike wetting pattems are also formed through the small pores of the matrix. The diameter of the patterns exceeded the width of individual cracks. indicating that the surrounding matrix was participating in the vertically directed flow as well. These preferred pathways are thought to form at places with cracks which receive relatively large amounts of water, due to water moving over the surface and through the surface layer towards slightly lower places. Hence, the the surface and through pores in the marrix can be wetted as well, resulting in irregular surrounding small pores in the matrix can be wetted as well, resulting in itregris wetting patterns. As a consequence of these parterns, variability in soil mois-ture content is high. We found large differences in soil moisture content in the heavy clay and peat soils in all tayers sampled at all the sites and for all measurements. Large differences in wetrability exist between wet and dry soils, due to water repellency being

induced at low water contents. Resistance to wetting was determin
wetting rate of field-moist samples with varying water contents.

\section{MODELLING OF WATER INFILTRATION AND SOIL SWELLING IN A VERTISOL FROM GUADELOUPE.}

S. Ruy ${ }^{1}$ Y.M. Cabidoche ${ }^{2}$ and L. Di Pietro"

1.3. INRA - Unité de Sciente du Sul - Domaine St Paul - Agropare - 8491 Ayignon Cedex 9 - FRANCE. 'Email: ruy @avignon.inra.fr. 'Email Avignon Cedex '2 INRA - Unité APC - Domaine Duclos - Prise D'eau 97170 Peit Models of water infiltration in undisturbed swelling soils rely on a dual porosity concept: Darcy flow in the micro (matric) porosity and by-pass flow in cracks. In vertisols from the humid tropics, a third component must be added; the structural porosity, excluding cracks. formed by the soil microfauna activity and containing water easily available for plants. A model was implemented to study the mecanisms of water infiltration: (i) wale was implo in marric porosity is modelled by the Darcy law, (ii) the flo in the in the sisctions. Water movemen cracks is instantaneously added at he botrom of the cralk into soil matrix are from structural to matric porosity and from crack's wall into soil matrix ase accounted for. Cracks opening is a function of soil matrix moisture. Shrinkage curve, retention curve and hydraulic conductivity of the matrix were measured in the laboratory. The anisotropy ratio of soil deformation was measured in situ. Experiments were conducted in situ to fit some soil structure parameters and test the model. Although not wholly validated because of a poor modelling of infiltration in structural porosity, the model already shows that infiltration in this soil is a 3D process and that water infiltration in structural infortiction in the main factor of rainfall partion in porosity is tarir and water flow into the eracks. Therefore, new researches should focus on water flow in structural porosity.

INFILTRATION OF WATER INTO SOIL WITH CRACKS: MODEL DESCRIPTION AND RESULTS OF MODELING.

V. Novák (Institute of Hydrology, Slovak Academy of Sciences, P.O. Box 94 Raciansk 75, 3008 Bratislava, Slovak Republic)

J. Śimủnek (U.S. Salinity Laboratory, 450 W. Big Springs Road, Riverside, CA 92507, U.S.A.)

Results of modeling of precipitation water infiltration into soil with cracks are Results of modeling of precipitation wa presented, as well as short description of the model FRACTU by joint elfort of the U.S. Salinity Laboratory and by the Institute of Hydrology Slovak Academy of Sciences. The model. FRACTURE is based on the two simultaneously running infiltration processes: infiltration into soil through soil

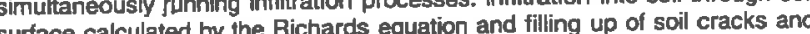
surface calculated by the Richards equation and soil matrix, using Green folfowing infiltration of this water horizontally into soil matrix, using Green Ampt approach. This process is involved in Richards equation as a source term. To quantity cracks infiltration two additional information are needed: so called shrinkage curve, which is the relation between crack porosity and soil called shrinkage curve, which is the relation bracks on the soil surface. The next water content and specine length of solicrion will be parametrization of the task in improving of the model application needed as input data to the model FRACT

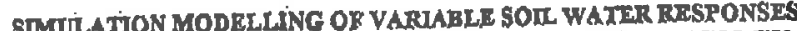
TO RATEATI IN A CRACKNG CLAY SOTL, BRMMSTONK FARM, UK.
M.Momum (1), Chris Bradley (1) and John Gerrard (1)

School of Geography and Environmontal Sciences, University of Birmingham, Edgbaitön, Bimingham B15 2TT, United Kingdom.

This paper will make use of an extonded data-tet comprising readings of soll whter tencion from an area of $9 \mathrm{~m}^{2}$ which bas been instrumented with 4 nest of 3 tensiometers for an 18 month period at Brimstone Farm, near Faringdon in the UK. The tensiometers have been comected with a Scanivalvo fluid switch, and read sequentially evory 2.5 minutes over 45 minute interval. Supplementary data include soil moisture readings from Neutron Moisture Probe, precipitation, net radiation, temperature and relative husuidity. The soil at this site is a cracking clay characterised by the seasonal development of sirinkage cracks which inhibit any generalisation of soil water flow. A sumnary of field-work result will be provided, which clearly indicate the influence of macropores in determining soil water response to rainfinl! of varying magnitude. The way in which theses datu are able to direct the devclopment of a process-response model for specific tensiometer nests will be described, and their general applicability will bo

MANAGEMENT OF SOIL WATER IN TEMPERATE CLAY SOILS: MOLE DRAINAGE AND THE ROLE OF STRUCTURE

A.C.Armstrong \& G.L.Harris

ADAS Hydrology. Gieadthorpe Research Centre, Mansfield NG20 9PF UK

Clay soils in temperate environments present difficulties in mangement, although rewarded by high agricultural yields. Artificial drainage is essential for the rewarde successful caltivato which has the effect of both improving the structure and the use of mole drainage, which has the effect of both improving the structure and providing an unlined drainage channel in the soil. However, the

of soils also leads to the prospect of rapid leaching of pollutanis. This paper will review experience in the experimental techniques required an sudy the hydrology and water quality of such soils: and the devel
predict the leaching of pesticides and nitrates from these soils.

DERIVING PARAMETERS FOR THE DETERMINATION OF MACROPORE FLOW IN CLAY SOIL

W. Al-Souri, Research Scientist, Helsinki Universily of Technology. P.O.BOX

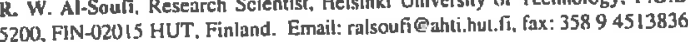

Field investigations carried out in Sjökulla Experimental Station located south of Fintand have shown that only the macropore flow of the soil is significant due to the Finland have som soil. Field experiment was cartied out to extremely lowe pernetrical configuration of the mueropores using the dye agent investigare the Brilliant Blue gathered have shown that water entrapment in cracks may rean up to $70 \%$ of the cotal rainfall. That amount of warer losses depends mainly upon the dryness of the lopsoil which initiates the opening of the "cracks mouth". A method for calculating the macropore flow in clay soil has been developed. Drain flow records, surface runoff, evapotranspiration and rainfall measurements over a considerable period of time have been used to construct the model. Physical characieristics of the catchment were lumped in one parameter called a retardation factor ( $\boldsymbol{k})$. In addition, another par paramerer The thescribed as a function of rainfall and

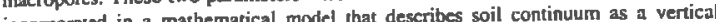
incorporad in a eylinder. Conventional models. which do not consider water eniapments in cracks, may overestimate water discharge from the catchment and ultimately overestimate pollution impact on rivers and lakes. In light of the testing results, the model can serve as a useful tool for calculating water and solute balance in agricultural clay soil. However, further field investigations are still being carried out to establish better parameverization to the water losses in discontinuous cracks.

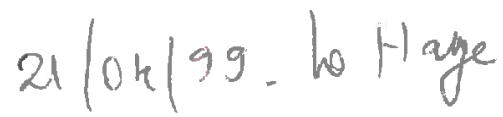

